\title{
LA PROTECCIÓN DE MENORES MIGRANTES NO ACOMPAÑADOS. UN MODELO DE INTERVENCIÓN SOCIAL
}

\author{
JOSÉ R. BUENO ABAD \\ Facultad de Ciencias Sociales, Universitat de València.
}

\section{FRANCISCO J. MESTRE LUJÁN}

Red de Centros Municipales de Servicios Sociales de Atención Primaria, Ayuntamiento de Valencia. Facultad de Ciencias Sociales, Universitat de València.

\section{RESUMEN}

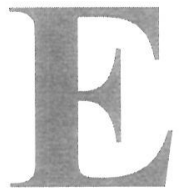

ste artículo supone una reflexión sobre las causas y características que rodean a la migración de menores no acompañados, con una vocación práctica sobre los cambios que deberían producirse para proporcionar a estos menores la protección a la que tienen derecho, dada su condición de menores de edad. Por ello, se propone un modelo de intervención basado en la gestión integral, desde los servicios sociales de atención primaria y especializada, al objeto de afrontar el problema con un esquema de funcionamiento garantista de los derechos del menor.

Este planteamiento sólo es aplicable, desde el punto de vista de los autores, adoptando una perspectiva comunitaria y multicultural de la inmigración y la aplicación prioritaria de la figura legal de situación de desamparo, prevista al efecto, tanto en el ordenamiento español como en la legislación internacional.

\section{MIGRANTES, IDENTIDADES EN TRÁNSITO}

La problemática construcción multicultural de Europa se encuentra enmarcada, en gran medida, por la historia de la formación de los diferentes Estados nacionales que la configuran. La conciencia nacional relacionada con la territorialidad o la percepción de un pasado o un idioma común han sido las bases para la formación de ese conocimiento de los pueblos que se traduce socialmente en leyes, derechos de ciudadanía, tradición y valores de pertenencia o exclusión. De modo diferente, otros países han tenido en los flujos migratorios una sólida base para la creación de sus Estados, conformándolos, de este modo, sobre la multiculturalidad y la diversidad de razas y credos. Por ello, y a diferencia de estos países, los Estados europeos perciben los flujos migratorios actuales de un modo peculiar, es decir, desde una óptica vinculada a la formación histórica y social de su cultura nacional específica. 
Históricamente, en Europa, las aportaciones migratorias de otros pueblos han sido interpretadas culturalmente como invasiones de pueblos inferiores, que han arrasado de forma súbita creaciones políticas y culturales superiores de la conciencia humana. También las migraciones de la población rural durante el siglo XIX hacia las ciudades europeas eran percibidas por sus habitantes como una invasión de gentes incultas, hacinadas en lugares insalubres, vinculadas a una tasa de procreación excesiva e incapaces de integrarse en la cultura refinada de las élites urbanas. El impacto provocado en la conciencia colectiva de las poblaciones aún puede verse reflejado en los relatos de Dickens, donde aparecen bandas de menores viviendo en la calle, que rechazan la escolarización y cuyo medio de vida es el robo y la infracción del orden público. De igual modo, los grabados de Doré nos describen esas masas sobrevenidas de comedores de patatas, que se hacinan en los suburbios de las ciudades y en los guetos de la periferia urbana, rodeados de humo y del olor hediondo de las fábricas cercanas (Ragon, 1971). Y, sin embargo, estos flujos migratorios supusieron, en gran medida, el nacimiento de la cultura popular y democrática, la consolidación de los partidos de masas y la modificación de las condiciones sociales, políticas y de valores que aceptamos hoy como constitutivas de la normalidad.

Las imágenes sociales de estas migraciones anteriores se han anclado en el acervo simbólico de nuestra cultura y condicionan la opinión pública, que las reelabora para explicar y comunicar los flujos migratorios actuales como si de invasiones bárbaras se trataran (Sartori, 2000; De Lucas y Torres, 2002; Bueno Abad y Belda Ibáñez, 2005).

Pero la migración del siglo XXI tiene rasgos específicos que la hace diferente de las anteriores. En la década de los sesenta y setenta del siglo pasado,

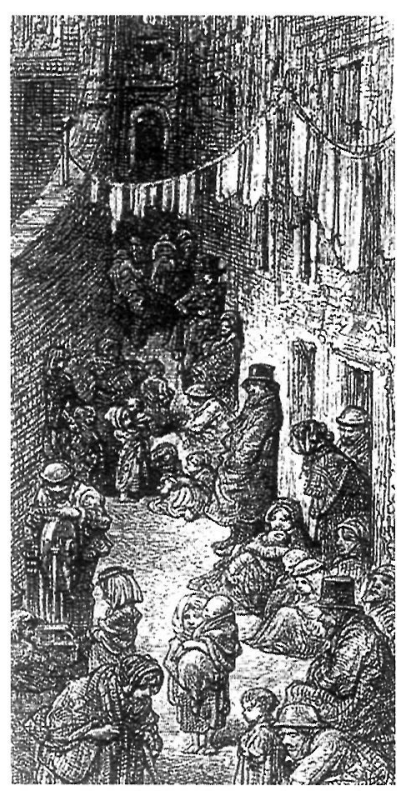
en el continente europeo asistíamos a una sociedad que, de modo incipiente, se conectaba por medio de los nuevos medios de transporte, los sistemas de comunicación y una estructuración supranacional de los mecanismos de intercambio de mercancías y capitales. Por primera vez, la migración de esa época se podía plantear la posibilidad de inmigrar sin romper del todo con las redes sociales y familiares que dejaba en el país de origen. Estos inmigrantes vivían la pérdida como un alejamiento continuado que, sin embargo, no era ya compatible con su proyecto migratorio. En realidad, eran nuevos ciudadanos de un universo no delimitado por las referencias territoriales nacionales, convirtiéndose, de hecho, en los primeros ciudadanos de un mundo de nuevas relaciones, que les convertía en extraños en su tierra natal y en extranjeros en el país de acogida.

La década de los ochenta transformó los flujos migratorios internos en Europa, les pro-

La migración rural en las ciudades, según un grabado de Doré. 
porcionó las características que identifican a aquellas migraciones del tercer mundo: que tienen como destino el llamado mundo desarrollado. Este modelo incipiente de redes transnacionales (Basch et al., 1994) es hoy una realidad tangible. Las vías de circulación y los medios de transporte modernos, los avances en los sistemas de comunicación y telefonía y la gran facilidad con que se producen los movimientos de mercancías y capital permiten ya la existencia de estructuras sociales que se asientan en un espacio de interrelación social que ya no se basa sobre una única territorialidad nacional. Por eso, en la actualidad, el proyecto migratorio es un proyecto doble, ya que involucra expectativas, objetivos y estructuras culturales, familiares y sociales en dos o más naciones, en un continuo temporal y territorial indeterminado (Tezanos, 2004).

Este "mundo cero"l está formado por personas que construyen sus redes familiares, su identidad y su proyecto vital en la intersección de diferentes contextos culturales, vinculando de este modo las comunidades de origen con las de destino en relaciones personales, familiares y sociales insertas en los procesos de globalización actuales. Los cambios tecnológicos les permiten comunicarse con sus familias de modo cotidiano, les resulta posible mantenerse informados por los medios de comunicación, vía satélite y en su propio idioma, sobre los acontecimientos que involucran a sus países de origen, por lo que este flujo de información contante condiciona su proyecto migratorio de manera directa y continuada, así como las decisiones personales y familiares que deben ser asumidas. De igual modo, pueden enviar parte de sus salarios de forma regular, manteniendo un vínculo constante, material, emocional y simbólico con el mundo de relaciones familiares y personales que dejaron atrás. Incluso pueden adquirir en el país de acogida los productos que les eran familiares en su tierra natal. Las propias empresas de estos países se trasladan a las naciones receptoras para promocionar y vender sus productos a estas "colonias" de ciudadanos con un poder adquisitivo más elevado que en el territorio de origen. Por otro lado, su proyecto migratorio incluye frecuentes desplazamientos, en ambas direcciones, de los miembros de las redes familiares, que se ven de este modo inmersas en relaciones que superan el marco del Estado nacional.

Las características de este "mundo cero" son variadas. Esta comunidad supranacional, cuya "institución" más propia es el locutorio (territorio multilingüe donde se experimenta la cercanía de la locución continuada con familias y amigos, se encargan y se reciben mercancías, se mandan mensajes y se negocian destinos familiares y envíos económicos), no es identificable con áreas geográficas concretas. En realidad, forma parte de los otros "mundos" que identificamos con escaso rigor, con categorías ordinales sin pertenecer a ninguno de ellos en concreto. Es, por tanto, una forma de experiencia vital y relacional globalizada, donde origen y destino se intercambian en un continuo temporal.

Otra de sus características es que, en esencia, estos migrantes atrapados en el "mundo cero", cuando se encuentran en situación irregular, frecuentemente deben negar su origen nacional al objeto de evitar la repatriación, al mismo tiempo que no obtienen el reconocimiento de ciudadanía plena en los países

1 Usamos este término en su dimensión cualitativa, puesto que el fenómeno al que nos referimos tiene la misma virtud que esta cifra, al modificar el elemento con el que se relaciona. 
receptores. Cuando, por el contrario, se encuentran en situación regular, el prejuicio hacia los inmigrantes en los países de acogida facilita que la reivindicación de sus orígenes nacionales sea algo limitado a la esfera de la intimidad individual o familiar, o bien se manifieste con respuestas que comunican un bienestar importante sobre el país recpetor, sin que ello suponga su aceptación genuina, sino, más bien, una actitud motivada por la deseabilidad social y por la aceptación formal que evite un mayor rechazo de la sociedad receptora (Contreras, 1994).

En otros casos, se opta por reivindicar en el espacio social, modos y costumbres característicos de su país natal que se encuentran descontextualizados en los países de acogida, pero que, sin embargo, se mantienen por su carga de significado identitario. Como se describe en Bueno Abad y Belda Ibáñez (2005), son procesos enmarcados en la "huida étnica" que expresa la aceptación acrítica de la cultura dominante del país de acogida o bien la formación de "identidades de oposición activa", adoptando valores de confrontación o de cohesión identitaria en los márgenes de la integración social. En este contexto de socialización transnacional, con un contenido intercultural insuficiente o inexistente, entre la aculturación y el prejuicio, se favorece la aparición de las manifestaciones sociales y políticas más extremas, reforzando con ello esa identidad dual de la "no man's land" en la que se hallan inmersos.

Ambos elementos los convierten necesariamente en un movimiento demográfico que subvierte la idea localista del Estado nacional y modifica considerablemente las instituciones básicas de la modernidad, esto es, la propia idea de nacionalidad territorial, pero, también, aquellas instituciones que la caracterizan como factores de socialización e interiorización de identidades nacionales homogéneas, como son la familia nuclear, la escuela y las relaciones contractuales de producción y consumo.

En la medida en que los flujos migratorios se estabilizan en los países receptores, la comunicación continuada con las naciones de origen permite que adultos y menores inicien procesos de reagrupación familiar que, en su trayecto, desarrollo y consolidación, implican a varias naciones. Son aspiraciones en los que están involucrados los padres, las personas cercanas a las redes familiares o cualquier integrante de la familia extensa. Son proyectos de migración cuyo futuro está sujeto tanto a la estabilidad de las redes familiares en el país de acogida como a la situación de las familias en el país de origen y, también, a la capacidad adaptativa del propio menor que, en no pocas ocasiones, se convierte en la punta de lanza de la migración posterior de nuevos familiares, o bien en piedra angular del éxito de la integración de su familia en el país receptor.

La casuística al respecto es altamente heterógenea; así, estas migraciones incluyen la existencia de familias monoparentales, nucleares y reconstituidas, cuyos hermanos, nacidos en diferentes países, pueden no conocerse entre sí. Familias separadas por largos periodos de tiempo que modifican sus relaciones emocionales y de parentalidad. Reagrupamientos familiares en familia extensa donde el rol parental es compartido a distancia. "Retornos" de menores que han nacido en el país de acogida al seno de sus familias cercanas en el país de origen e, incluso, diferentes y repetidos tránsitos de menores que no con- 
siguen adaptarse a las nuevas relaciones familiares y sociales en los países de recepción. Toda esta amalgama de diferentes situaciones plantea un proceso dinámico correspondiente a una adaptación forzada y cambiante, vinculada al nivel de estabilidad conseguido en el país de acogida. De este modo, los afectos se globalizan, escapan al marco normal de una identidad nacional y cultural y el proyecto vital individual y familiar trasciende de este modo las fronteras nacionales de una manera perdurable en el tiempo, desnaturalizando con ello el apego y la pérdida, el duelo y la expectativa vivencial, los procesos de maduración y de asunción de roles.

Los habitantes de este "mundo cero" se encuentran, así, implicados en la creación de relaciones familiares e identidades individuales que sobrepasan las instituciones socializadoras de los Estados Nación, al quedar insertas en el tiempo y en el espacio a la indeterminación consustancial a su situación de habitante dual del "mundo cero". Su propia condición de migrantes dificulta la auto-identificación con una ciudadanía nacional concreta o con un proyecto vital socializador que vaya más allá de las cambiantes y azarosas condiciones que impone una identidad en permanente tránsito.

\section{LAS DIMENSIONES DE LA MIGRACIÓN DE MENORES EN ESPAÑA}

Las condiciones de un mundo con un mercado global, donde los países en vías de desarrollo se han desarmado arancelariamente ante el tráfico comercial de los países desarrollados, la existencia de pandemias generalizadas, como el VIH, que diezman a la población en África y Asia, la falta de respeto a los derechos humanos y la inestabilidad política, junto a una imagen mediática acrítica del mundo desarrollado, determinan la continuidad de los flujos migratorios hacia las economías más desarrolladas. En este contexto, el proyecto migratorio implica un traslado paulatino de las redes familiares de la población, lo que determina que no siempre los adultos vayan acompañados de sus respectivos hijos. Esto supone la existencia en nuestro país de menores acompañados por adultos y menores migrantes no acompañados que, igualmente, emprenden el tránsito migratorio confiando en el reconocimiento de sus necesidades y expectativas en las naciones de acogida.

Realizar la migración a otra nación con menores supone dificultades en cuanto a conseguir una vivienda apropiada y una escolarización accesible. Además, limita la movilidad geográfica y la disponibilidad horaria del migrante, lo que reduce su potencial de empleabilidad. A ello, hay que sumarle las restricciones temporales y legales al reagrupamiento familiar y las propias limitaciones del migrante, dependiendo de la situación administrativa en que se encuentre en el país de acogida. Esto implica que, en la medida en que las primeras migraciones se asientan con éxito en el país receptor, la presencia de los menores va aumentando de modo paulatino.

\subsection{La cuantificación de los menores no acompañados}

En lo que respecta a la presencia de menores no acompañados, los datos disponibles son fragmentarios y puntuales, dada la dispersión de las agencias 
de protección existentes en cada ámbito autonómico. En lo que respecta a las frecuencias de este flujo migratorio, según la intervención parlamentaria recogida por los medios de comunicación consultados, correspondiente al 6 de julio de 2005, en el que llegaban a nuestras costas casi medio centenar de menores no acompañados, desde enero a marzo de 2004, habían sido detectados en situación de acceso irregular 114 menores no acompañados. En 2005, y para el mismo periodo, se habían contabilizado 147 menores, lo que supone un aumento del $53 \%$ respecto al año anterior. Al día siguiente, arribaban a nuestras costas una veintena más de menores como rúbrica palmaria de este aumento constante de la llegada de menores inmigrantes no acompañados a nuestro país. Además, la Comisaría General de Extranjería y Documentación, dependiente del Ministerio del Interior, daba un número total de menores migrantes no acompañados de 415 menores llegados e nuestro país en 2004.

El segundo trimestre de este año, se producía un salto cuantitativo importante en el aumento de menores no acompañados. Así, el periódico El País, de 19 de julio de 2005, citando a Antonio Camacho, Secretario de Estado para la Seguridad, cifraba los menores llegados en patera a nuestras costas en el primer semestre de 2005 en 365 , lo que supone un aumento del $123 \%$ respecto al mismo periodo del año anterior. Lo cierto es que, frente a estas cifras, ya de por sí preocupantes, el proyecto Conred (2004), dentro del programa europeo Daphne (2000-2003), indicaba para países como Francia, Suiza, Italia, Bélgica y España una afluencia aproximada de menores solos de entre 1.000 y $2.000 \mathrm{al}$ año para cada uno de ellos.

En cuanto al número total de menores migrantes no acompañados en España, la misma información periodística recogía la cifra de 1.575 menores, como resultado del registro de menores en Centros de Acogida. Aunque esta cifra puede contener diferentes ingresos repetidos de los mismos menores, lo cierto es que el Comunicado del III Encuentro Ciudadano Estatal en defensa de niñas, niños, adolescentes y jóvenes no acompañados, celebrado en noviembre de 2003 en Madrid, haciendo mención a la instrucción de la Fiscalía 3/2003, alertaba de que su cumplimiento podía haber supuesto la repatriación de 3.000 menores migrantes no acompañados que, en esa fecha, estaban ya en España. En el mismo artículo, Micaela Navarro, Consejera de Igualdad y Bienestar Social de la Junta de Andalucía, cuantificaba la existencia de 1.400 menores no acompañados solo en Andalucía, sin contar otras Comunidades como Madrid, Cataluña o el País Valenciano. En este sentido, el Ararteko, institución análoga en Euskadi al Defensor del Pueblo, cifraba en 2.118 los menores no acompañados atendidos en el País Vasco a lo largo de 9 años (El País, 08/09/05), de los que 192 se encuentran en situación de acogimiento.

En este contexto, las mismas fuentes periodísticas consultadas, de 9 de septiembre de 2005, informan que las comunidades autónomas tutelaron a 11.411 menores inmigrantes no acompañados en el periodo comprendido entre el 1 de enero de 2004 y el 30 de junio de 2005. De este total, 8.624 de estos menores fueron acogidos en Andalucía, Valencia, Cataluña y Madrid por este orden. Durante el mismo periodo, sólo obtuvieron autorización de residencia en nuestro suelo 831 de estos menores. 
En resumen, a la vista de estas cifras tan contradictorias, si observamos cómo el número de tutelas confirman las cifras dadas por Conred, en lo que respecta a una afluencia a nuestro suelo de menores no acompañados de entre 1.000 y 2.000 menores al año, con aumentos en los niveles de llegada superiores al 100\% interanual; con unos dos mil menores en situación de acogimiento, en la actualidad, de los que sólo apenas el $7 \%$ obtienen el certificado de residencia.

En lo que respecta al caso español, el perfil característico de los menores no acompañados se refiere a un menor mayoritariamente originario de Marruecos $(80 \%)$ y de los países del Magreb, con una presencia muy inferior de menores provenientes de países del Este europeo. De entre 15 y 18 años, varón, con familia o conocidos en nuestro país y con una situación de partida determinada por la precariedad económica y la falta de expectativas laborales en su país de origen. A diferencia de las creencias más extendidas al respecto, aunque este menor pasa gran parte de su tiempo en la calle, ha sido escolarizado en los niveles primarios del sistema educativo y cuenta con la tutela de su familia en el país de origen que envía a este menor a la inmigración, consciente de las dificultades que podría tener en acceder a otro país después de la mayoría de edad. Por otro lado, la llegada de menores en patera permite suponer la existencia de redes familiares a uno y otro lado del Estrecho que financian este tipo de inmigración (Ramírez Fernández, A.; Jiménez Álvarez, M.; 2005), utilizando para ello los contactos con las redes de inmigración ilegal (los "tarrak" del puerto de Casablanca o los "timoneros" de Ceuta y Melilla).

Los problemas de este colectivo de menores, derivados del perfil descrito, son aquéllos relacionado con la existencia de expectativas distorsionadas e indefinición personal de su proyecto migratorio, problemas de integración en el medio escolar y baja o nula cualificación laboral, desconocimiento del idioma y la cultura del país receptor, problemas para su ubicación en redes familiares de acogida, la socialización por medio de la pertenencia a grupos de iguales y el consumismo como única alternativa de integración y el rechazo o abandono reiterado de los proyectos de acogimiento residencial, propiciando con ello un marco anómico de desarrollo personal y de exclusión social.

Todas ellas son características que les sitúan en el arquetipo social decimonónico de los menores de la calle que viven del delito, que son indisciplinados por naturaleza y guardan en su interior un potencial delincuente, ante los que las medidas más adecuadas son esencialmente el internamiento o la repatriación.

Durante este proceso psicosocial de explicación, atribución y resolución del problema, incluso las autoridades olvidan su condición de menores y se centran en su situación de inmigrantes irregulares. Lo paradójico es que este prejuicio social sea capaz de transformarse en leyes y políticas nacionales, como lo ejemplifica la mencionada instrucción de la Fiscalía, 3/2003.

\subsection{La cuantificación de los menores acompañados}

En lo que respecta a menores en situación regular, según el Boletín Estadístico del Observatorio Permanente de la Inmigración, correspondiente a marzo 
de 2005 , existen en España 280.756 menores de 15 años con tarjeta de residencia en vigor; de ellos, sólo 75.348 tienen residencia permanente.

Estadísticamente, el Ministerio incluye a los menores con más de 15 años en grupos de edad diferentes y agrupados con los mayores de 18 años, por lo que el número de menores de edad es, en realidad, sensiblemente mayor al registrado en las estadísticas oficiales.

Las dificultades de estos menores acompañados obedecen a diferentes variables, como el tiempo que, en su caso, la familia ha estado separada, la situación y el contexto familiar previo al reagrupamiento, la edad el menor, el número de hermanos separados, el tipo de familia formada o reestructurada en el país de acogida, así como la situación socioeconómica de la misma. Estas variables se traducen, en ocasiones, en problemas adaptativos de los menores a la cultura del país receptor, problemas idiomáticos, aculturación, formación insuficiente de redes de iguales, problemas psicológicos, conductuales y desadaptación escolar, que incluyen, en no pocas ocasiones, tanto conflictos familiares de relación como aprendizajes tempranos anómalos por la asunción de responsabilidades desproporcionadas al estadío de desarrollo del menor, o bien una integración laboral insuficiente por la falta de cualificación profesional, cuyo indicador más significativo es su temprano abandono de los grados medios y superiores del sistema educativo español (Bueno Abad y Belda Ibáñez, 2005).

En cualquier modo, y dadas las características descritas, ambos colectivos se encuentran inmersos en un espacio social que favorece el riesgo de exclusión social (Castel, 1999) y que permite, a partir de estos nuevos procesos de socialización transnacionales, la acomodación de estos menores en un espacio anómico, donde las creencias y los valores que forman la individualidad y su proyecto evolutivo vital no se vinculan a ningún sistema social y cultural concreto.

\section{EL PROCESO DE INMIGRACIÓN DE MENORES NO ACOM- PAÑADOS Y EL SISTEMA DE PROTECCIÓN ESPAÑOL.}

En primer lugar, debe mencionarse que, en el ordenamiento jurídico español referido a la protección de menores, la activación del sistema recae sobre la calificación de dos conceptos fundamentales: la situación de riesgo, que implica una intervención social sobre los factores que la originan, y la situación de desamparo, cuya consecuencia legal es siempre la declaración de tutela automática por parte de la agencia de protección, y el acogimiento familiar o residencial subsiguiente del menor, como puede verse con detalle en el esquema de la página siguiente.

En todo caso, lo que supone la declaración de desamparo es la tutela directa del menor por parte de la Administración y su acogimiento en familia o Residencia, hasta que desaparezca la situación que la originó o el menor alcance la mayoría de edad.

Esto significa que una política no restrictiva de declaración de desamparo que califique de este modo la situación de los menores no acompañados requie- 


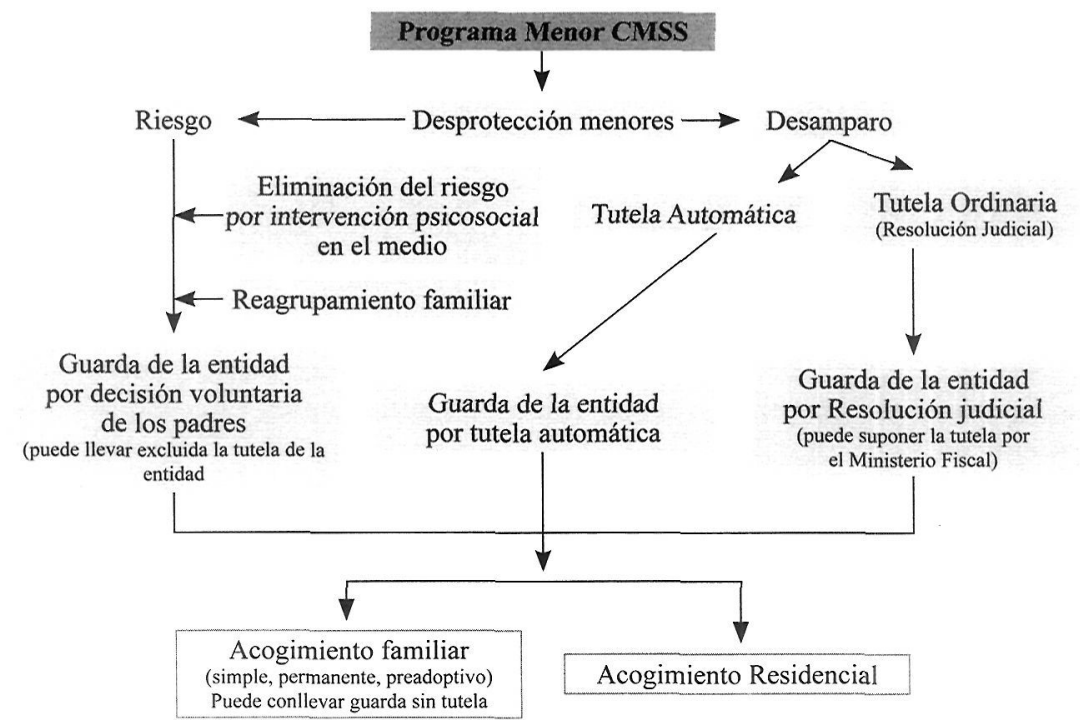

GRÁFICO 1. Sistema de Protección de Menores desde un CMSS.

re la existencia de una importante disponibilidad de recursos residenciales y el empleo de abundantes recursos personales y materiales para promover y evaluar posibles acogimientos familiares. Sin embargo, la asunción por parte de nuestro país, de la Resolución del Consejo de Europa de 26 de junio de 1997, que califica a todos los menores con acompañados llegados desde terceros países en situación de desamparo, no permite, a nuestro entender, la aplicación de otras medidas de protección que no sean las inherentes a la declaración de tutela automática, precisamente por su condición de menores solos sin guarda y tutela identificables de su familia.

No obstante, el sistema español de protección del menor se encuentra presidido por un principio fundamental consistente en que el niño debe permanecer integrado con su familia biológica. Este axioma se halla implícito en nuestra carta magna (art. 39), en la Ley 1/96 de Protección del Menor y en toda la legislación autonómica derivada de esta normativa básica. De acuerdo con este principio, la opción preferente de las autoridades españolas, ante la presencia irregular de un menor no acompañado, es la de gestionar su repatriación, al objeto de hacer efectiva la guarda y custodia del mismo en el seno de su familia natural, y en este sentido van las instrucciones de la Fiscalía 3/2003 y 6/2004 de 26 de noviembre.

Abundando en este loable empeño por favorecer el núcleo relacional, incluso por encima del interés del menor, nos encontramos con el hecho paradójico y contradictorio con dicho principio que encarnan las actuales restricciones al reagrupamiento familiar contenidas en la legislación sobre extranjería, en cuanto a plazos temporales y administrativos que la hacen parsimoniosa y restrictiva en el país de acogida, y la existencia en nuestra Constitución, en el mismo art. 39.4, de la obligatoriedad de aplicar las normas internacionales so- 
bre protección de menores, lo que incluye de facto la mencionada Resolución del Consejo de Europa.

El hecho es que este principio indiscutible de favorecer la estancia del menor con su familia biológica se vuelve discutible cuando no implica la repatriación del menor hacia el país de origen. Seguramente, cuando se restringe de este modo el reagrupamiento familiar en el país de acogida se tienen muy en cuenta ejemplos como el de Francia, en el que el 80\% de la inmigración recibida accede al país vía reagrupamiento familiar.

Por otro lado, la defensa del reagrupamiento familiar sólo cuando implica la repatriación del menor muestra cómo este principio es entendido con un criterio restrictivo y respecto a su condición de inmigrantes irregulares, implícito en la Ley 4/2000 sobre Extranjería y su Reglamento de ejecución (RD. $864 / 01$ ), y no sobre su condición de menores solos, y totalmente a espaldas de las características de las relaciones transnacionales ya mencionadas, produciendo con ello múltiples efectos perversos que incluyen la negativa del menor a proporcionar datos sobre su identidad, escapadas continuas de los Centros de Recepción (en ocasiones, de la totalidad de los menores registrados en estos recursos) y también nuevos intentos reiterados de entrada ilegal en nuestro país de los mismos menores, inmersos en una creciente dificultad para realizar la migración.

De este modo, todo el proceso por el que pasan los menores a su llegada irregular a nuestro país se encuentra determinado por tres elementos básicos:

- La aplicación parcial y restrictiva de la legislación que protege al menor en situación de desamparo frente a la aplicación prioritaria de aquellos principios que evitan la declaración de tutela automática de los mismos, con la subsiguiente obligatoriedad de la Administración de ejecutar medidas de acogimiento residencial o familiar, por encima de las consideraciones sobre la repatriación o no del menor.

- La falta de una política de concesión de certificados de residencia ligada al cumplimiento de un proyecto de inserción y renovable periódicamente de acuerdo con proyectos personalizados de integración social y laboral.

- La falta de recursos, personal e iniciativas coordinadas centradas en la integración de los menores inmigrantes, considerados prioritariamente como menores objeto de tutela y especial protección.

El proceso de acceso irregular al que nos referimos normalmente se inicia con la detección del menor por las fuerzas de seguridad, aunque, en ocasiones, es el propio menor quien acude por iniciativa propia a dar constancia de su existencia. Posteriormente, la Fiscalía propicia la investigación sobre la edad del menor y su identificación inicial. Sólo después de identificar la edad del menor y probada su minoría de edad, éste pasa a estar bajo la supervisión de las agencias autonómicas de protección de menores.

A partir de este momento, el menor ingresa en un Centro de Recepción o recurso similar, mientras que continúa la investigación sobre su identidad y familia de origen y se analizan las posibilidades de repatriación o la valoración de aquellas condiciones que aconsejen su ingreso en un recurso específico de 
protección de menores, bajo la guarda y tutela de la agencia autonómica de protección, previa declaración de situación de desamparo.

Pero, para hacer efectiva este decisión, el menor debe identificar su identidad y origen, con el conocimiento de que, si presta dicha información, posiblemente será repatriado. Por ello, la negación de su identidad y la huida de los Centros de protección se convierten en factores característicos y prioritarios para el éxito de su proyecto migratorio $y$, por tanto, inherentes a la política aplicada a la migración irregular de menores no acompañados.

Además, en el caso de menores finalmente repatriados, debe tenerse en cuenta que aquéllos que acuden en patera a nuestro país cuentan con la financiación y consentimiento de su familia a ambos lados de la frontera, lo que implica que la familia, posiblemente, volverá a intentar disponer el viaje del menor antes de su mayoría de edad. Por otro lado, no es infrecuente que menores repatriados que, en principio, contaban con el apoyo de su familia, ante el futuro perjuicio económico de un nuevo intento, decidan quedarse en las zonas portuarias de Tánger, Ceuta y Melilla, esperando realizar el viaje, esta vez, en la trasera de algún camión o escondidos en los bajos del mismo, siguiendo así la misma ruta que los menores "de la calle", que realizan su migración sin apoyo familiar alguno.

Por tanto, la existencia de una política restrictiva de inmigración priorizada sobre la aplicación de las normas de protección de menores favorece la aparición, consolidación y generalización de:

- Estrategias defensivas de ocultación de aquellas señas que caracterizan la identidad e individualidad.

- Imposibilidad en la mayoría de los casos de reagrupamiento familiar en el país de origen y su aplicación diferida en el país de acogida.

- Indefensión del menor en situación de desamparo.

- Abandono de los recursos de protección de menores.

- Existencia en nuestro país de menores y jóvenes migrantes en un espacio de exclusión social.

Estas situaciones son las que definen principalmente la problemática sobre menores migrantes no acompañados y, por tanto, se constituyen en los elementos básicos que debería afrontar cualquier modelo alternativo de intervención con este colectivo. Por otro lado, a la vista de las consecuencias del modelo actual, la reflexión sobre su continuidad o modificación legitiman el debate sobre otras formas de pensar y replantear el hecho migratorio en su conjunto y, particularmente, en lo que respecta a la protección de menores y a esta nueva forma de relaciones familiares transnacionales que caracterizan las migraciones actuales.

\section{IV: UN MODELO DE APLICACIÓN DEL SISTEMA DE PROTEC- CIÓN A LOS MENORES MIGRANTES NO ACOMPAÑADOS}

El modelo que vamos a describir parte de las insuficiencias observadas en el proceso aplicado en la actualidad. Supone el reconocimiento prioritario de la 
condición de menores no acompañados de estos niños y preadolescentes y, por tanto, de la aplicación automática de las medidas contenidas en la declaración de situación de desamparo. Este enfoque permite un cambio radical que implicaría modificaciones en las leyes de extranjería, la adecuación de los centros de protección de menores a este hecho específico y el desarrollo de políticas supranacionales que involucran a los países de origen $\mathrm{y}$, sobre todo, $\mathrm{y}$ en nuestro caso, a aquellas políticas migratorias a desarrollar con los países del Magreb.

Ya en el momento en el que el menor es detectado por las fuerzas de seguridad e iniciadas las instrucciones en Fiscalía para su identificación, el menor debe contar con la ayuda y supervisión de mediadores culturales que le informen de su situación y de la voluntad del Estado de facilitar su protección ayudándole en su proyecto migratorio.

Comprobada su minoría de edad, el menor debería ser trasladado a un Centro de Recepción. Este recurso debe coordinar y proporcionar las primeras asistencias en cuanto a necesidades básicas, residencia, control sanitario y filiación de su proyecto migratorio que, fundamentalmente, se concreta en la investigación e identificación preliminar sobre la existencia o no de redes familiares o conocidos en nuestro país o la carencia de ellas. El objetivo es proporcionar información a los menores sobre la disponibilidad de ayudarles a facilitar su proyecto migratorio y proveer la información inicial suficiente que permita actuar a los Centros Municipales de Servicios Sociales de Atención Primaria que existan en la zona.

Estos Centros Municipales de Base deben concretar la situación de desamparo con la agencia de protección autonómica, y la tramitación subsiguiente, con la colaboración de los servicios sociales especializados de inmigración, de la documentación del menor, que permita su estancia legal en el país. Documentación que debe ser renovable y condicionada al compromiso del menor y a su particular situación, y vinculada a su implicación y participación en el proceso que, de este modo, desde el principio, se convierte en un proceso de acogida pautado, solidario e integrador, sobre todo en aquellos casos en los que el menor no tiene una familia de acogida o está inmerso en un proceso de reagrupación familiar.

La estancia en los Centros de Recepción, por tanto, debe reducirse al mínimo posible. Recogida esta información inicial, puesta en marcha la declaración de desamparo, bajo la supervisión de los servicios sociales de atención primaria, el menor debe ser derivado a un recurso residencial normalizado y adecuado a este colectivo, donde prime la formación laboral y educativa sobre otras consideraciones, se adecue a la edad del mismo y se conecte con servicios especializados de formación e integración prelaboral, dentro de un plan individualizado. Estos recursos deben velar por mantener y potenciar los primeros contactos del menor con sus comunidades de referencia en el país de acogida, de manera que todo el proceso esté presidido por la implicación personal, la multiculturalidad y la falta de elementos de aculturización.

En este contexto, los centros municipales de servicios sociales de base deben mantener un contacto continuo con el menor, al objeto de determinar, analizar, evaluar e impulsar los posibles reagrupamientos o acogimientos familiares en nuestro país. 
Por tanto, los objetivos fundamentales de la intervención se concretan en proporcionar al menor, por medio de un proceso participado, de la guarda y tutela necesarias a través de la declaración de la situación de desamparo, la regulación administrativa de su situación y el acogimiento o reagrupación en redes familiares o sociales idóneas y cercanas al mismo, preferiblemente, antes de su mayoría de edad, como lo muestra de forma esquemática el gráfico siguiente.

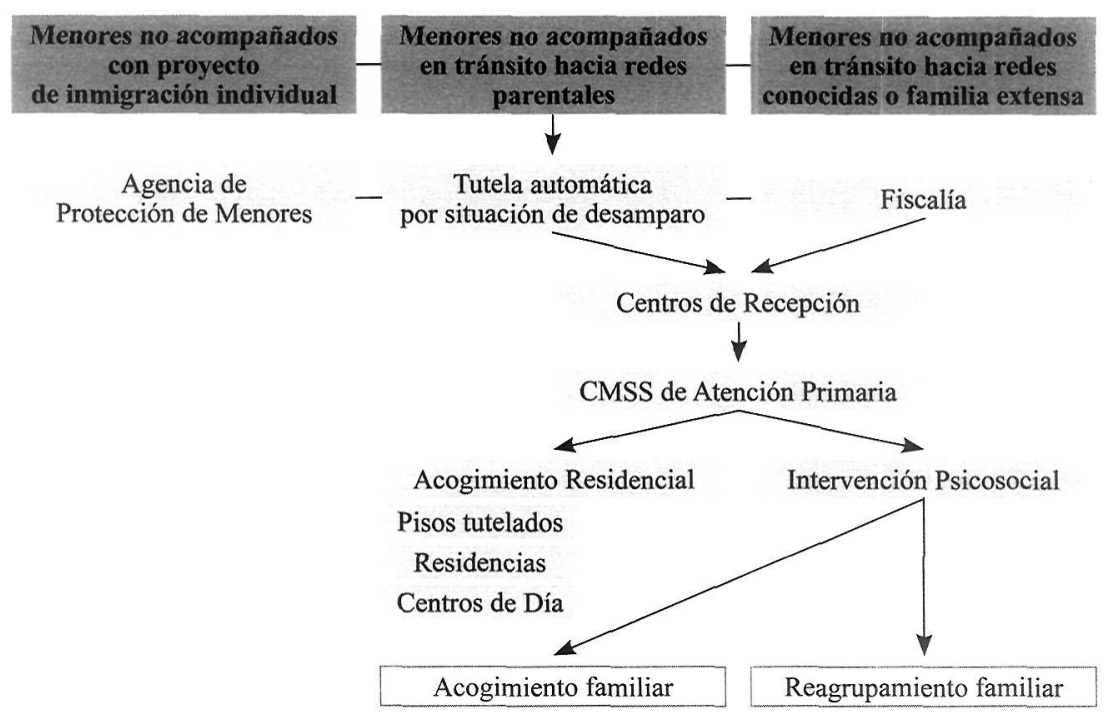

GRÁFICO 2. Proceso de protección de menores migrantes no acompañados.

Puesto que éste es también el objetivo del menor, el abandono de los recursos residenciales se minimizaría de forma considerable. Sin embargo, existen objeciones importantes en el desarrollo de este modelo.

La primera de ellas está determinada por la existencia de un pequeño número de menores migrantes no acompañados que no cuentan con redes sociales ni familiares en el país de acogida. Una traslación aproximada, y con todas las reservas, hacia la complejidad del proceso de integración situaría esta cifra en torno al 15\% de los menores inmigrantes no acompañados (Ramírez, A. y Jiménez, M., 2005). Por otro lado, también concurre el caso de que existan menores que, aun contando con apoyo social o familiar en el país de acogida, éste no sea el idóneo para el correcto desarrollo del menor. Por último, puede darse el caso de que el menor no acompañado esté en tránsito por nuestro territorio hacia un tercer país de destino.

Si, por último, descartáramos la posibilidad de su inclusión en una familia acogedora, pensamos que estos son los casos, cuando concurran en ellos una demanda activa de la familia en el país de origen o se constate su aprobación al retorno del menor, en que se vuelve prioritaria y oportuna la exploración de las familias de origen y la aplicación de una eventual repatriación, ya que, en todos ellos, ésta es la única medida que permite ofrecer al menor la protección contenida en el art. 39 de nuestra Constitución. Estos casos hacen necesaria la 
existencia de redes de Casas de Acogida en los países emisores de la migración infantil, similares a la red YMCA que existe en la actualidad a lo largo de la frontera entre México y EUA.

Aunque esta es una iniciativa loable y oportuna, es necesario ser conscientes de que alrededor de estas residencias suelen generarse tejidos mafiosos y de prostitución infantil que alientan la continuidad de la migración irregular de menores no acompañados y no aseguran la permanencia de los menores en las mismas (la estancia media es de entre 2 y 8 días). Por lo que, a nuestro juicio, una eventual repatriación debe sopesarse siempre, ponderando la situación y oportunidades con que el menor, en las situaciones anteriormente descritas, va a contar en su país de origen, y siendo siempre preferible la potenciación del reagrupamiento familiar o de los programas de familias acogedoras que permitan afrontar este problema en el país receptor.

La segunda objeción importante tiene que ver con el posible "efecto llamada" que puede ser capaz de generar, ya que, en esencia, el modelo presentado facilita la regularización y permanencia de los menores, primando con ello la migración irregular como vía de acceso y consolidación del proyecto migratorio en los países de acogida.

Sin embargo, esta consideración debe ceder ante los hechos. La migración irregular de menores es ya una vía consolidada y preferible a enfrentarse a las restricciones migratorias después de la mayoría de edad. Además, estas políticas no han permitido un descenso migratorio en el número de menores solos. Este es un fracaso ya observado, aunque incipiente en España y totalmente constatable en otras zonas de frontera, como México, Canadá o EEUU, como ponía de relieve un estudio del Sistema Nacional para el Desarrollo Integral de la Familia mexicano, que señalaba cómo "en lo que va del año han sido repatriados más de 6 mil pequeños, por lo que se calcula que al final de 2000 la suma ascenderá a casi $15 \mathrm{mil}$. Además, se ha incrementado la participación de las niñas y adolescentes en la migración indocumentada, al pasar de $21 \%$ en 1999 a $27 \%$ en el primer semestre de 2000 , lo que equivale a una relación de tres mujeres por cada 10 varones. Por otro lado, en los últimos dos años (2000-2001) aproximadamente el $40 \%$ de los menores inmigrantes no acompañados son adolescentes y jóvenes de 14 a 17 años" (Conferencia Regional sobre Migración, 2002).

La descripción de las causas que generan estas insuficiencias de las políticas de inmigración actuales nos retrotraería a la descripción de ese "mundo cero" al que aludíamos al principio de este artículo y que describe la existencia de redes familiares trasnacionales que no se rompen por la presencia de las actuales fronteras nacionales.

Por otro lado, los problemas sociales que está generando el modelo actual se verían sensiblemente disminuidos al aumentar y adecuar los recursos sociales en protección de menores en mayor medida que en dirigir un gasto similar o superior en políticas de orden público o de judicialización de esta problemática.

Por último, el aumento de la inmigración tiene en sí misma elementos estructurales que aseguran su continuidad. Así, algunos de los países donde se 
origina la inmigración ilegal, y en especial Marruecos, obtienen una importante fuente de riqueza nacional con las transferencias de ahotro de sus inmigrantes (Ramírez Fernández, A.; Jiménez Álvarez, M., 2005). Este mismo país se ha convertido en territorio de paso de la migración subsahariana, recibiendo presiones continentales para convertirse en la frontera sur de la fortaleza europea, lo que va a requerir, sin duda, la coordinación global con todos los países del Magreb en cuanto a las directrices y cooperación en la gestión de los flujos migratorios no sólo para conseguir la disminución de los mismos sino, más bien, para que éstos no aumenten desproporcionadamente en cantidad y complejidad (Maríe, 2003). Algo que implicará, sin duda, la transferencia de riqueza, recursos y competencias hacia los países involucrados en este problema y un trato político diferente del mismo.

A la postre, lo que en este sentido planteamos se basa en la prioridad de aplicar una nueva forma de entender la inmigración de menores no acompañados desde una perspectiva psicosocial y comunitaria y sin reducir el problema a declaraciones o disposiciones legalistas. Esta propuesta se encuentra dinamizada por tres principios claros, como son, en primer lugar, el necesario direccionamiento de una fracción de la riqueza, debida, en parte, a los mismos inmigrantes que residen y trabajan ya en nuestras ciudades, hacia la inversión y adecuación de medidas sociales referidas a la protección de menores, ajustando su complejidad y capacidad a los cambios demográficos y sociales que la propia migración ya ha hecho realidad palpable en nuestro país.

En segundo lugar, en la aplicación automática de la tutela y del derecho a la residencia, vinculado este último con un proyecto personalizado de integración social, así como en el fortalecimiento de los programas de reagrupamiento y acogimiento familiar. Por último, nos basamos en la ampliación de la política migratoria nacional y comunitaria a un marco territorial supranacional de inversión y cooperación del que ya gozan otras políticas nacionales, de las que no se discute su utilidad en este mundo globalizado dentro de un contexto de ciudadanía cosmopolita o transnacional.

El marco teórico global que anima estas propuestas es el correspondiente a la visión de un proyecto europeo en construcción en sus aspectos culturales, sociales, económicos y territoriales, donde la multiculturalidad y la aplicación real de los derechos humanos son signos irrenunciables y característicos de los valores de la identidad europea.

\section{BIBLIOGRAFÍA}

BASCH, L.; GLICK SHILLER, N.; SZANTON BLANC, C. (1994), Nations unbound. Transnational Projects, Postcolonial predicaments and deterritorialized Nation-States, Pensilvania, Gordon \& Breach Sciencie Publishers.

BUENO ABAD, J.R.; BELDA IBÁÑEZ, J.F. (dirs.) (2005), Familias inmigrantes en la escuela. Discursos de los agentes educativos. Valencia, Ed. Servei de Publicacions, Universidad de Valencia.

CASTEL, R. (1999), La metamorfosis de la cuestión social. Una crónica del asalariado. Barcelona. Paidós. 
Conferencia Regional sobre Migración, Menores Migrantes: Derechos Humanos, Protección y Servicios en los países miembros de la Conferencia Regional sobre Migración. Estudio conjunto México y Canadá (2002), http://www.crmsv.org/investigacion/Can-MexEstudioFinalE spa $\%$ C3\%Blol.doc.04/06/05

Conred (2004), Seminario Europeo. Menores migrantes no acompañados en Europa. Conclusiones. Barcelona, 12, 13 y 14 de mayo. Impulsor del proyecto.

CONTRERAS, J. (comp.) (1994), Los retos de la inmigración. Racismo y pluriculturalidad. Madrid, Ed. Talasa.

Departamento de Proyectos Sociales de la Pere Tarrés / Universidad Ramón Llull, Barcelona.

DE LUCAS, J.; TORRES, F. (2002), Inmigrantes. ¿Cómo los tenemos? Algunos desafios y malas respuestas. Madrid, Talasa Ediciones.

MARÍE, C.V. (2003), Prévenir l'inmigration irréguliére: entre imperatifs económiques, risques politiques et droits des persones. Comité Europeo sobre Inmigraciones. Consejo de Europa, Estrasburgo. 03/03.

RAGON, M. (1971), Historia mundial de la Arquitectura y el Urbanismo modernos, Tomo I. Ideología y Pioneros 1800-1910. Barcelona, Ediciones Destino.

RAMIREZ FERNÁNDEZ, A.; JIMÉNEZ ÁLVAREZ, M. (coord.) (2005), Las otras migraciones: la emigración de menores marroquies no acompañados en España. Universidad Internacional de Andalucía. Madrid, Edit. Akal.

SARTORI, G. (2000), La sociedad multiétnica. Pluralismo, multiculturalismo y extranjeros. Madrid, Taurus.

TEZANOS, J.F. (2004): Revolución tecnológica y cambios socio-culturales. Nuevas identidades en las sociedades tecnológicas avanzadas. En TEZANOS, J.F. (ed.): Tendencias en identidades, valores y creencias. Séptimo foro sobre tendencias sociales. Madrid, Sistema. 